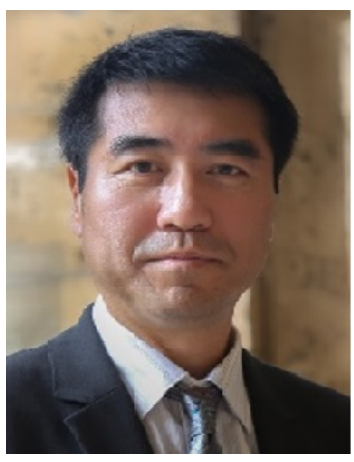

\title{
Acoustics and Sustainability: A Built Environment Perspective
}

Sustainability refers to the coexistence of the biosphere and human civilization, where the use of resources, the way of investments, the development of technologies, and institutional changes are all in harmony, and "meet the needs of the present without compromising the ability of future generations to meet their own needs" (United Nations General Assembly, 1987). Acoustics deals with sound waves in gases, liquids, and solids and its application is present in almost all aspects of modern society, from both a physical and human perspective. It is, therefore, of great significance to consider how research of acoustics and its applications could become an integrated part of sustainability. In this editorial, those are explored from the built environment perspective, in terms of acoustic comfort, urban sound planning, building-envelop designs, sustainability of acoustic materials and products, use of natural means for noise reduction, and the acoustic impacts of sustainable measures.

Acoustic comfort is an important part of the overall physical comfort, a key consideration in a sustainable built environment. If there are acoustic defects in an indoor or outdoor space, remedial treatments are often costly and inefficient. At an urban scale, along with the EU Environmental Noise Directive 2002, mandating each city to identify and protect its quiet areas, there has been a recognized lack of research in urban soundscapes, integrating the conventional physical approach with the consideration of perceived sound environment, as the conventional approach of merely reducing the noise level often does not deliver an improved quality of life (e.g. during the COVID-19 lockdown the sound level decreased by 10-15 dBA in London whereas noise complaints doubled). In addition to controlling noise, introducing pleasant sounds is very important. At a building scale, acoustic quality and comfort is not only important in acoustic buildings such as auditoria and recording studios, but also in everyday 'non-acoustic' buildings such as hospitals, schools, sport centers, churches, offices, libraries, and shopping centers.

In planning a city, sound propagation needs to be taken into account. There is an increasing urban population and correspondingly higher building density, and the construction industry accounts for $1 / 3$ of our total energy consumption. Although higher building density will normally bring a higher noise level, a comparison between a typical high density city in China (with a major road grid of $500 \mathrm{~m}$ by $500 \mathrm{~m}$ ), and a typical low density city in the UK (with many evenly distributed smaller roads), shows that, while the spatial maximum noise levels in the former are mostly higher than those in the latter, the spatial average and minimum noise levels in the latter are generally higher (Appl. Acoust., 2011;72:556-568). This suggests that with a given density, there is a great potential of planning the urban morphology to make a city more noise resistant. Another solution is to develop self-noise-protection buildings by designing appropriate building shapes.

Designing sustainable building-envelops is also related to acoustic issues. For example, a window with two or more layers of glazing could bring benefits in both energy saving and noise reduction. On the other hand, encouraging the use of natural ventilation is an important aspect of the green building movement, but opening windows can often cause noise problems. It is thus important to develop window systems that reduce noise transmission while allowing natural ventilation as well as efficient use of daylight, thus increasing the overall sustainability of the building stock. There have been various attempts to produce suitable systems using passive (Appl. Acoust., 2005;66:669-689) and active control techniques (J. Acoust. Soc. Am., 2011;130:176-188; Sci. Rep., 2020;10:10021), as well as their combinations.

Various acoustic materials and products, including absorbers, insulators, diffusers, silencers, and noise barriers, may have similar acoustic performances but very different characteristics in terms of sustainability. It is therefore important to carry out lifecycle analysis and environmental impact assessment for acoustic materials and products (Build. Environ, 2009;44:2166-2175). A number of acoustic products have also been developed by using recycled materials such as tires and carpets, and by using natural materials (Appl. Acoust., 2020;159:107070), to achieve better sustainability.

Using natural means to reduce noise will also significantly contribute to the overall sustainable development, for example, with vegetated surfaces (applied to building façades and roofs), caged piles of stones (gabions), vegetation belts (tree belts, shrub hedges), earth berms, and various ways of exploiting ground-surface-related effects (Appl. Acoust., 2015;92:86101; 2020;165:107328). The acoustic effects of vegetation arise through three mechanisms: sound absorption and sound diffusion, which occur when a sound wave impinges on the vegetation and is then reflected back; and sound level reduction, when a sound wave is transmitting through the vegetation. When used on boundaries within a street canyon or square, the effectiveness of absorption and diffusion can be greatly enhanced since there are multiple reflections.

Some sustainable measures, such as wind farms, may be noisy, so the useable land is reduced and the overall sustainability could be negatively affected. It is thus important to examine the noise generation and propagation of such measures, as well as the perception of such noise sources (Renew. Energy, 2017;107:629-638; Landsc. Urban Plan., 2017;165:1$10)$.

Overall, given the above interrelationships between creating comfortable sound environments and maintaining sustainable developments, acoustics should be an essential consideration in sustainability, where there are a range of research and application potentials, from basic research for new materials to design methods and techniques, and also, it is important to integrate acoustics into various standards and regulations on sustainability.

$$
\text { Jian Kang }
$$

Jian Kang, FREng, FIIAV University College London 